\title{
Cultural Variations in the Glass Ceiling Effect: A Review
}

Ragitha Radhakrishnan*

\begin{abstract}
Gender Disparity is a universal phenomenon. The effect is more evident in an organisational setup. Two common forms of gender disparity are sticky floor effect and glass ceiling effect. Glass ceiling effect refers to the barriers that prevent women from progressing to the higher positions in the organisations. It can lead to differences in pay and may prevent women from climbing up the career ladder. The barriers may be psychological, social or organisational. The paper discusses the presence of glass ceiling across different cultures and its implications
\end{abstract}

Keywords: Glass Ceiling Effect, Gendered Hiring Protocols, Employment and Organisation Processes

\section{Introduction}

Gender differences affect the social relationships between men and women and vary with time and culture (Ahamed \& Naseer, 2015). Gender stereotypes or sex-role stereotypes are collective attitudes that men are better suitable to winning on leadership roles and positions of authority and power while women are dissimilar for the taking of nourishing and serving arrangements (DeArmond et al., 2006). Discrimination, negative attitudes and stereotypes of women as leaders prevail, which are the major reasons for fewer

* Department of Psychology, Dr MGR-Janaki College of Arts \& Science for Women, Chennai, India; ragitha.radhakrishnan@gmail.com 
opportunities and slower career progress for women (Koshal et al., 1998; Nath, 2000; Merrell \& James, 2001; Cordano, 2002).

According to the Global Gender Gap Report released by the World Economic Forum (WEF) in 2011, India was ranked 113 on the Gender Gap Index (GGI) among 135 countries polled. Since then, India has improved its rankings on the World Economic Forum's Gender Gap Index (GGI) to 105/136 in 2013. Similarly, UNDP has published Gender Inequality Index and ranked India at 132 out of 148 countries.

\section{The Glass Ceiling Effect}

Lamp (2001) refers to glass ceiling as the invisible or artificial barrier that prevents women from being promoted to the highest positions in organisations, regardless of their abilities and achievements. It is a form of discrimination against women. Though the glass ceiling is generally used to denote discrimination in the workplace, it is a result of the social and economic inequalities that prevail in the society (Wirth, 2000). Linehan and Scullion (2001) mentioned that many jobs are still seen as men's or women's jobs and this influences the initial intake of a particular gender to organisations. Individual variables such as gender, marital status, employment of husband and number of children have an impact on work and family conflict resulting in the formation of a glass ceiling (Cinamon \& Rich, 2005). In India, women efforts and competencies are not highlighted because stereotyping behavior exists in our culture and also reflect in planning that hampers their chances of promotions (Jabbar \& Imran, 2013).

The barriers that hinders women from progression to higher positions may be visible or invisible (Al-Manasra, 2013). It is considered to be a form of gender discrimination (Bell, McLaughlin \& Sequeira, 2002). The glass ceiling is a multifaceted phenomenon because it is the cause and effect of multiple factors. Sometimes the causes and effects are visible, but sometimes they are hard to notice (Tran, 2014). Breaking the glass ceiling is necessary to bring out the full potential of woman employees in any organisation. 
Haiu and Kee (2008) consider the glass ceiling as a way of discrimination against women. According to Haslam and Ryan (2008), there are three fundamental reasons for the formation of the glass ceiling in organisations. First, men are inclined to prefer other men for leisure and public support mechanisms as 'gay sociality' and self-expression. Secondly, there is an existence of sexist attitude that is prevalent among men that men are best suited in leadership roles than women (Acker, 1990). The third reason is the perception about women as one who has the role of childbearing and childcare responsibilities; women as a group remain absent from work more frequently than men (Amuedo-Dorantes \& De la Rica, 2005).

\section{Studies related to Psychological Glass Ceiling}

Nick (1999) had performed a longitudinal study on the women who were taking on a global career. His findings revealed that there are visible indications that women are still more in low-grade organisational provision compared to men. This also proved a sturdy glass ceiling result in a worldwide content. Baxter and Wright (2000) explored the hypothesis that the relative rates of women being promoted to higher levels compared to men should decline with the level of the hierarchy with data from three countries: the United States, Australia, and Sweden. The basic conclusion was that while there is strong evidence for a wide gender gap in authority - the odds of women having authority are less than those of men-there is no evidence for systematic glass ceiling effects in the United States and only weak evidence for such effects in the other two countries.

To investigate the wage gap for employment in Pakistan, Sabir and Aftab (2007) studied the progression of the wage gap in Pakistan from 1996-1997 to 2005-2006. However, the prime aim of their study was to give some insights into the gender pay gap by recent economic development. The study revealed that, although the recent economic accomplishments had opened gates for women in the workforce, this inclination had also broadened the wage gap.

The primary purpose of the exploration of Haiu and Kee (2008) in Australia was to examine the differences between the wage allocations. His research revealed that glass ceiling ruled more in 
the private sector than in the public sector of Australia. The reason was the family-friendly atmosphere in the public sector of Australia. Abidin, Rashid \& Junoff (2009) attempted to discover the obstacles that keep women from rising above a certain level in the organisations with an effort to raise both their self-worth and the level of their contribution towards economic development. They discovered that five main factors influence the career progression: structure, task, commitment, social, and culture.

Purcell et al. (2010) conducted research in Sweden to verify whether sticky floors and glass ceiling's sound effects affect women. They instituted throughout their research that women in Sweden conceded accumulation of the sticky floor consequences than glass ceilings. Ahmad and Naseer (2015) investigated gender discrimination by means of sticky floors and glass ceiling effects in the public and private sectors. The study conducted on two types of organisations in Islamabad, public and private, regardless of the nature of the work. Female members faced biased behaviour not only from their immediate authorities but also from their contemporaries at the workplace. The study has also confirmed that there is a gender bias in promotions in the public and private organisations.

Cansu Akpinar-Sposito (2013) studied the glass ceiling issues and the main career obstacles for female executives based on the findings of a cross-country comparative study between Turkey and France. Differences in career barriers for women between countries resulted because of personal compromises, career encouragers, and corporate culture. Bombuwela and Chamaru (2013) studied the effects of glass ceiling on career development of women in private sector organisations in Sri Lanka. Following the study results, a conclusion was eventually made that there are significant effects of the glass ceiling on career development of women at the executive level for female employees working in private sector organisations in Sri Lanka.

Bimba and Kaliyamoorthy (2015) conducted research that proves that the glass ceiling is present in Indian IT organisations. It was found that obstacles associated with breaking through the glass ceiling included more nuanced forms of gender stereotyping, tokenism, and sexual harassment. Majority of women being 
recruited for upper-level positions were exposed to high risk of failure. Sever (2016) expressed that women confront the glass ceiling syndrome much more than men. The factors affecting the glass ceiling were identified as gender, age, marital status, promotion, working in the public or private sector and additional income. She concluded that these unseen barriers prevent women from promotion and workforce. The findings by Khuong and Chi (2017) reveal that the glass ceiling does exist in Vietnamese corporations as well. The impediments to career development of women emerge in three main dimensions: management perception, career progression and growth, work environment.

\section{Conclusion}

The paper intended to reflect whether glass ceiling exists in the 21st century or not and whether it exists in different cultures. Glass ceiling does exist which creates the barriers that prevent women from reaching top positions. The barriers may be psychological, social-relatedg or organisational (Bimba \& Kaliyamoorthy, 2015). Due to the invisible glass ceiling, women are hired for the entrylevel positions and underrepresented in administrative works. Women employees are denied the opportunity to receive mentorship as well. The societal setup and the mindset of the patriarchal society make women's career a matter of secondary importance. Though the government is working towards the upliftment of the women the implementation of these policies needs scrutiny. One of the strategies to ensure inclusivity would be to promote and pay according to the skill and objective measurements in performance appraisals which could resist discrimination. Demolition of the glass ceiling will result in gender equality in our society in the real sense.

\section{References}

Abidin, Z. Z., Rashid, A. A. A., Jusoff, K., (2009). The 'Glass Ceiling' phenomenon for Malaysian women accountants. Asian Culture and History, 1(1), 38-44.

Acker, J. (1990). Hierarchies, jobs, bodies: a theory of gendered organizations. Gender and Society, 4(2), 139-158. 
Al- Manasra, E.A. (2013). What are the "Glass Ceiling" barriers effects on women career progress in Jordan? International Journal of Business $\mathcal{E}$ Management, 8(6), 40-46.

Amuedo-Dorantes, C. and De la Rica, S. (2005). The impact of gender segregation on male-female wage differentials: evidence from matched employer-employee data for Spain. IZA Discussion Papers, No. 1742.

Baxter, J., \& Wright, E. O. (2000). The glass ceiling hypothesis: a comparative study of the United States, Sweden, and Australia. Gender E Society, 14(2), 275-294.

Bell, M.P., McLaughlin, M.E., \& Sequeira, J.M. (2002). Discrimination, harassment and the glass ceiling: women executives as change agents. Journal of Business Ethics, 37, 65-76.

Bimba, F. \& Kaliyamoorthy, S. (2015). Barriers of glass ceiling on women employees in IT sector. Jnanavardhini - Online Multi Disciplinary Research Journal, 58-64.

Bombuwela, P. M., \& Chamaru, A. (2013). Effects of glass ceiling on women career development in private sector organizations - case of Sri Lanka. Journal of Competitiveness, 5(2), 3-19.

Cansu, A. (2013). The glass ceiling: structural, cultural and organizational career barriers for French and Turkish women executives. Le 24ème congrès de l'AGRH 2013, Paris, France.

Cordano, M., Scherer, R. F., \& Owen, C. L. (1994). Attitudes toward women as managers: sex versus culture. Women in Management Review, 17(2), 51-60.

DeArmond, S., Mary, T., Peter, Y. C., Autumn, K., \& Emily, S. (2006). Age and gender stereotypes: new challenges in a changing workplace and workforce. Journal of Applied Social Psychology, 36(9), 2184-2214.

Gender Gap Report. (2011). World Economic Forum, page 9

Global Gender Gap Report. (2013). World Economic Forum. Archived from the original on 31 March 2014.

Haslam, S. A., \& Ryan, M. K. (2008). The road to the glass cliff: differences in the perceived suitability of men and women for leadership positions in succeeding and failing organizations. The Leadership Quarterly, 19(5), 530-546. 
Insch, G. S., McIntyre, N., \& Napier, N. K. (2008). The expatriate glass ceiling: the second layer of glass. Journal of Business Ethics, 8, 19-28 Doi 10.1007/s10551-007-9649-0.

Jabbar, A., \& Imran, A. (2013). Perception of glass ceiling in the educational institution: An evidence from Pakistan. World Applied Sciences Journal, 23(5), 628-634.

Khuong, M. N. \& Chi, N. T. (2017). Effects of the corporate glass ceiling factors on female employees organizational commitment: an empirical of Ho Chi Minh City, Vietnam. Journal of Advanced Management Science, 5(4), 255-263.

Koshal, M., Gupta, A. K., \& Koshal, R. (1998). Women in management: A Malaysian perspective. Women in Management Review, 13(1), 11-18.

Linehan, M \& Scullion, H. (2001). Challenges for female international managers: evidence from Europe. Journal of Managerial Psychology, 16(3), 215-228.

Merrell, A. J., \& James, E. H. (2001). Gender and diversity in organisations: past, present and future directions. Sex Roles, 45(5/6), 243-251.

Nath, D. (2000). Gently shattering the glass ceiling: Experiences of Indian women managers. Women in Management Review, 15(1), 44-55.

Nick, F. (1999). Another 'Glass Ceiling'?: The experiences of women professionals and managers on international assignments. Gender, Work and Organization, 6(2), 79-90.

Purcell, D., MacArthur, K. R., \& Samblanet, S. (2010). Gender and the glass ceiling at work. Sociology Compass, 4(9), 705-717.

Sabir, M., \& Aftab, S. (2007). Dynamism in the gender wage gap: evidence from Pakistan. The Pakistan Development Review, 46(4), 865-882.

Sever, H., (2016). The comparison of glass ceiling perception of employees working in public and private enterprises. American Journal of Industrial and Business Management, 6, 577-588.

Tran, T.T.T. (2014). Identifying the existence of the glass ceiling and examining the impact on the participation of female executives in the Vietnamese banking sector. An unpublished thesis submitted in partial fulfillment of the requirements for the degree of Master of Business, Unitec Institute of Technology. 
Wirth, L. (2000). Breaking through the glass ceiling: women in management. Geneva, Switzerland: International Labour Office Bureau International du Travail. 